\title{
Melamine Medicated by Gastric Acid to Cyanuric Acid Lead to Kidney Damage and its Repair
}

\author{
Zheng $\mathrm{Qi}^{1, \mathrm{a}}{ }^{*}$, Miao $\mathrm{Yu}^{2, \mathrm{~b}}, \mathrm{Guosong} \mathrm{Xin}^{3, \mathrm{c}}$ and Yubin $\mathrm{Ji}^{4, \mathrm{~d}}$ \\ 1. Research Center on Lift Sciences and Environmental Sciences, Harbin University of commerce, \\ Harbin, 150076, China \\ aemail: 18645039597@163.com \\ bemail: yumiao913@163.com \\ cemail: 13766801150@163.com \\ demail: jyb@hrbu.edu.cn
}

Key words: melamine; kidney damage; gastric acid; repair

Abstract .This study focused on the melamine-cyanuric acid crystals formation by melamine does alone, and to explore the resource of cyanuric acid and kidney failure repair.

Method The $800 \mathrm{ng} / \mathrm{ml}$ melamine solution was individually regulated to $\mathrm{pH}$ value of $3,4,5$, and 6 placed in $37^{\circ} \mathrm{Cthermostat}$ water bath for acidification which simulated gastric conditions, the reaction time was set at 1,2, and 3 hours, the final solution was dried by nitrogen and tested by GC-MS to analysis the concentration of melamine medicated to cyanuric acid. 78 Wistar male rats of clean grade were randomly divided into the exposure group and control group, 60 rats in exposure group and 18 rats in control group. Melamine was given $25 \mathrm{mg} / \mathrm{kg}$ body weight through food in exposure group, 10 rats of exposure group and 3 rats of control group were individually taken for morphological observation after 2 weeks, 3 weeks, 5 weeks exposure, and 2 weeks, 6 weeks, 12 weeks repair after stopped exposure. Results Melamine can be medicated into cyanuric acid under the simulated gastric conditions. The concentration of melamine and cyanuric acid was appeared linear relationship with $\mathrm{pH}$ value and reaction time. Melamine exposure led to kidney failure, which melamine-cyanuric acid crystals blockage led to acute kidney injury, and it can be gradually restored without extra treatment after stop exposure. Conclusion Melamine can be medicated under the chemical reaction, kidney failure can gradually restored without treatment, which estimated the melamine decomposition to cyanuic acid under the action of gastric acid was one of the mechanisms leading to kidney injure.

\section{Introduction}

In 2007, incidents of pet food poisoning occurred in the United States, that scrap melamine(contaminated with related triazines including cyanuirc acid) were added to the feed ${ }^{[1]}$. And in 2008, similar incidents of infant milk powder took place in China, pure melamine added to the milk ${ }^{[2]}$ were confirmed the sources of the poisoning. As a result, the toxicity of melamine had attracted more attention.

Melamine is white oblique prism crystal at room temperature, slightly soluble in water and hydrolyzes in strong acid and alkali ${ }^{[3]}$. Melamine is an important chemical raw material ${ }^{[4]}$, mainly used to condensation with aldehydes, as raw material to produce melamine/formaldehyde resin (MF), this resin hardness is higher than urea-formaldehyde resins, non-flammable, water resistance, heat resistance, aging resistance, arc resistance, chemical resistance, good insulation properties , gloss and mechanical strength, widely used in wood, plastic, paint, paper, textile, leather, electric, pharmaceutical and other industries. Melamine can also be used as flame retardant, water-reducing agent, formaldehyde cleaning agents and so on. In some Asian countries, melamine has also been used to make fertilizers. an important chemical material ${ }^{[5]}$; LD50 is $3.16 \mathrm{mg} / \mathrm{kg}$.bw, which is low toxic substance ${ }^{[6]}$. The melamine and cyanuric acid are administered in combination, formation of melamine-cyanurate crystals occurs ${ }^{[7]}$. Due to the intratubular precipitation of crystals in the kidney, 
and the crystals obstruction caused by acute renal injure, resulting in renal tubular epithelial cell degeneration, necrosis, and accompanied by renal interstitial cell infiltration ${ }^{[8,9]}$. However, melamine alone exposure was also appeared melamine-cyanuric acid crystals obstruction in the kidney, by now, the ways of melamine convert to cyanuric acid are not clear. Zheng et al ${ }^{[10]}$ proved that gut microbiota converted melamine to cyanuric acid in vitro experiment, and colonization of rat guts with Klebsiella increases cyanuric acid concentrations. During the recovery period, the use of antibiotics significantly reduced crystals formation and renal function restored. However, this study aimed to discuss the melamine converted by gastric acid, the amidogen was gradually replaced by hydroxyl, and the final product was cyanuric acid, the rest melamine reacted with produced cyanuric acid formed melamine-cyanuric acid crystals. During the recovery period, to explore the kidney injury restore status of animal's body without any treatment.

\section{Material and Methods}

\section{Animals and Treatment}

The SPF Wistar male rats at 4week, the experimental animal license number was SCXK(Ji)2011-0004, the animal room license number was SUZK(Hei)2006-008. The animals' body weights were $80 \mathrm{~g} \pm 10 \mathrm{~g}$. There were 60 rats in exposure group and 18 rats in control group, the rats were housed individually. Animal rooms were maintained at $24^{\circ} \mathrm{C} \pm 2^{\circ} \mathrm{C}$ and $45 \% \pm 10 \%$ relative humidity.

\section{Che micals and Reagents}

There were no melamine and any other triazines (include cyanuric acid, ammeline and ammelide) tested in neither feed nor water, and melamine mixed in feed was chemical pure (99\%purity, Sinopharm Chemical Reagent Co., Ltd.). Melamine and cyanuric acid of reference substance for Gas chromatography mass spectrometry was analytical reagent (99\%purity, Agilent Technologies Company).

\section{Instruments}

Instruments utilized in the experiment included Agilent Technologies 7870AGC-7000MS, thermostat water bath, Hitachi 7080 automatic biochemistry analyzer.

\section{Method performance}

\section{Quantitative analysis of melamine converted by Hydrochloric acid by GC-MS}

Gas chromatography mass spectrometry (GC-MS) is an analytical chemistry technique that combines the physical separation capabilities of gas chromatography with the mass analysis capabilities of mass spectrometry. According to the peak time identify the substance and peak area calculate the concentration of melamine and cyanuric acid, followed the GB/T 22288-2008 Determination of melamine, ammeline, ammelide and cyanuric acid in original plant products-GC-MS method. In this method, melamine and cyanuric acid standard combination concentration were $40 \mathrm{ng} / \mathrm{mL}, 80 \mathrm{ng} / \mathrm{mL}, 200 \mathrm{ng} / \mathrm{mL}, 400 \mathrm{ng} / \mathrm{mL}$ and $800 \mathrm{ng} / \mathrm{mL}$. Melamine was prepared at the concentration of $800 \mathrm{ng} / \mathrm{mL}$, placed at $37^{\circ} \mathrm{C}$ thermostat water bath to simulated gastric conditions. As the gastric acid was mainly by hydrochloric acid, the $\mathrm{PH}$ values of melamine solution were regulated to 3, 4, 5 and 6 by hydrochloric acid and reaction times were 1,2 and 3 hours. The final solution samples were detected by GC-MS to quantitative analysis of the melamine and cyanuric acid. 


\section{Feeding experiment}

Melamine was administered in the diet to the mice for 4 weeks at dose of $25 \mathrm{mg} / \mathrm{kg} \bullet \mathrm{bw} / \mathrm{d}$ and the melamine mixing dose in feed was $250 \mathrm{mg} / \mathrm{kg}$. The mice of control group were fed by the same diet without melamine. Ten mice were taken from both control group and expose group after 2, 3 and 5 weeks, the recovery group after 2, 6, 12 weeks, individually, injected by pentobarbital to anaesthesia, and euthanized by cervical vertebrae dislocation. The serum was taken for Blood Urea Nitrogen (BUN) and Creatinine (CRE) biochemical detection, $0.5 \mathrm{~mm}$ section of anatomical kidney was observed under the anatomical lens. After fixation with $10 \%$ buffered formalin, the kidney tissues were embedded in paraffin. Serial sections were prepared and stained with Harris's hematoxylin and eosin (H\&E) for histopathological evaluation by light microscope.

\section{Statistical analys is}

The data was analyzed using STATA 8.0 by one-way analysis of variance (ANOVA) based on the data normality and homogeneity of variance to identify significant differences between groups. All data was expressed as Mean \pm SD. Further comparisons between the two groups, SNK test was used as the variance was neat, Games-Howell test was used as variance was not neat. There were statistically significant differences in $\mathrm{P}<0.05$.

\section{Results and Discussion}

\section{Qualitative analysis of melamine conversion}

The final solution samples after $\mathrm{pH}$ values of melamine solution were regulated to 3, 4, 5 and 6 by hydrochloric acid and reaction times were 1, 2 and 3 hours which were detected by GC-MS. Compared the standard melamine(Fig.1A) and cyanuric acid(Fig.1C), the solution samples after silanization were confirmed to contain melamine and cyanuric acid.
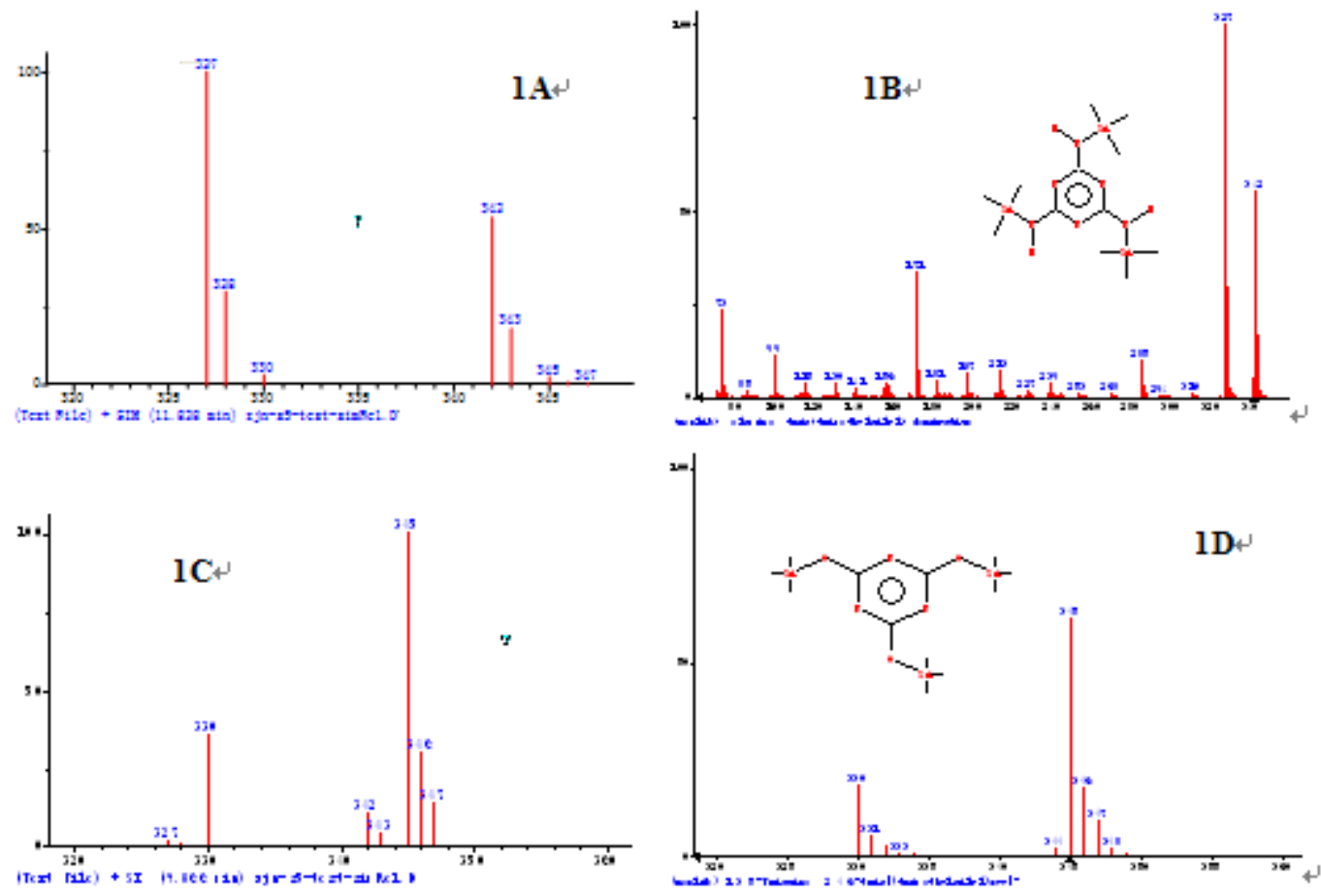

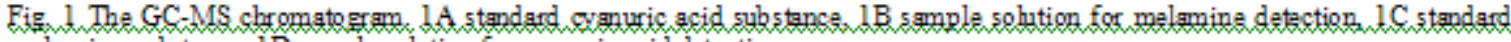
melamine substance, 1D sample solution for sxamuric acid detection.

The gastric juice was normally at pH3-6, the liquid and solid substances in gastric resistance time were 1 to 4 hours. Therefore the simulated gastric condition was $\mathrm{pH}$ value from 3 to 6 , reaction time was 1 to 3 hours at $37^{\circ} \mathrm{C}$. The initial concentration of melamine was $800 \mu \mathrm{g} / \mathrm{ml}$, under the 
hydrochloric acid condition, the concentrations of melamine and cyanuric acid in the final solutions were in Figure 2 and Figure 3. According to the Figures, the melamine concentration was decreased as $\mathrm{pH}$ value decreased and time increased. The melamine was gradually replaced by hydroxyl, and the final product was cyanuric acid, the concentration of cyanuric acid was increased as $\mathrm{pH}$ value decreased and time increased. It was confirmed melamine can transform to cyanuric acid under the simulated gastric condition, and the quantity and speed of transform was depend on $\mathrm{pH}$ value and reaction time.

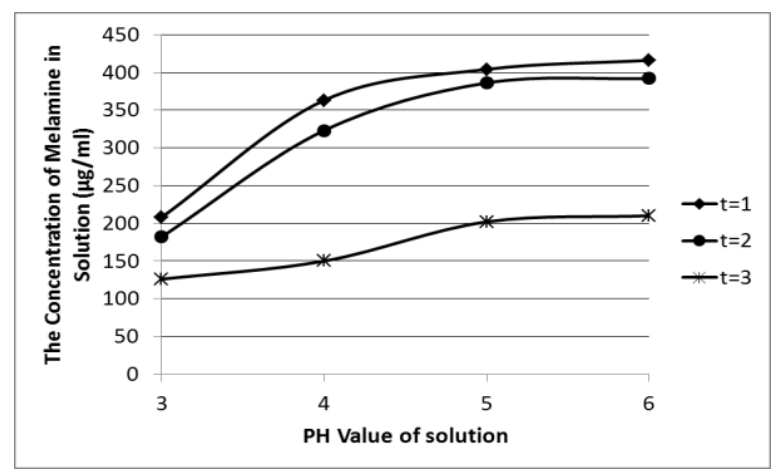

Fig.2The concentration of melamine in the sample solution tansformation under different $\mathrm{PH}$ values

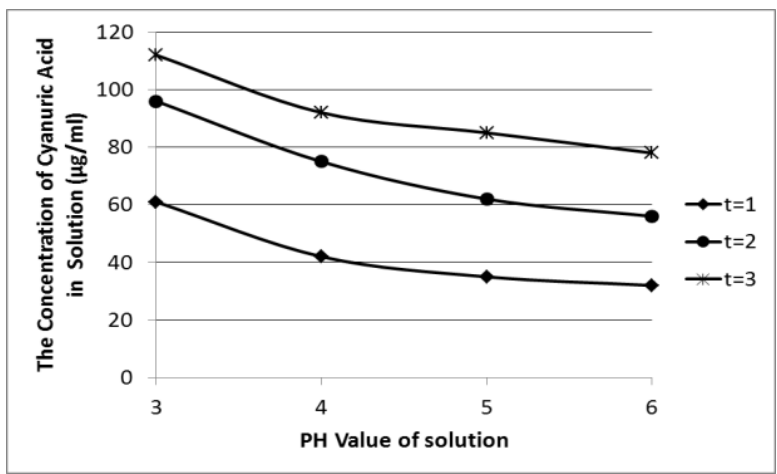

Fig.3The concentration of cy anuric acid in the sample solution tansformation under different $\mathrm{PH}$ values

\section{Morphological observation}

BUN, CRE of the serum compared with the control group after 2-week-dose were normal, with statistically insignificant ( $p>0.05)$. Two parameters after 3 and 5 weeks dose were unusually, and increased compared with control group, with statistical significance $(p<0.01)$, CRE of serum was unusually compared with control group after 2 -week-recovery $(p<0.01)$, both BUN and CRE of serum compared with control group after 6-week-recovery and 12-week-recovery were normal as shown in Table 1.

Table 1 Summary serum data of kidney in mice

\begin{tabular}{ccccc}
\hline \multirow{2}{*}{ Group } & Stage & $\begin{array}{c}\text { Time } \\
(\text { week })\end{array}$ & $\begin{array}{c}\text { BUN } \\
(\mathrm{mmol} / \mathrm{L})\end{array}$ & $\begin{array}{c}\text { CRE } \\
(\mu \mathrm{mol} / \mathrm{L})\end{array}$ \\
\hline \multirow{3}{*}{ Exposure group } & Dose Time & 2 & $6.44 \pm 0.73$ & $70.9 \pm 2.81$ \\
& Dose Time & 3 & $16.90 \pm 6.95^{*}$ & $124.4 \pm 34.73^{*}$ \\
& Dose Time & 5 & $37.15 \pm 9.67^{*}$ & $207.5 \pm 32.28^{*}$ \\
& Recovery Time & 2 & $13.67 \pm 3.62$ & $105.63 \pm 18.8^{*}$ \\
& Recovery Time & 6 & $7.42 \pm 2.08$ & $83.31 \pm 8.35$ \\
& Recovery Time & 12 & $4.61 \pm 0.73$ & $86.67 \pm 5.63$ \\
\hline \multirow{2}{*}{ Control } & Dose Time & 2 & $6.31 \pm 0.25$ & $69.7 \pm 2.83$ \\
& Dose Time & 3 & $5.82 \pm 0.38$ & $72.9 \pm 2.81$ \\
& Dose Time & 5 & $5.83 \pm 0.34$ & $69.8 \pm 4.64$ \\
& Recovery Time & 2 & $5.65 \pm 0.38$ & $74.00 \pm 2.81$ \\
& Recovery Time & 6 & $5.12 \pm 0.48$ & $73.16 \pm 3.25$ \\
& Recovery Time & 12 & $4.63 \pm 0.15$ & $77.67 \pm 3.51$ \\
\hline
\end{tabular}

Each value represents mean \pm SD $(n=10$, males and females combined).

${ }^{*} p<0.01$ compared to control group. 


\section{Renal tissues pathological examinations}

The renal tubular epidermis of control group was integrated and no crystals and inflammatory cells were observed inside (Figure 2A). The lesions after five weeks dose were severe, the renal tubular was in a large number of inflammatory cell infiltrated. The renal tubular expansion was more obviously and with a high degree of expansion that showed tubular epithelial debris around the crystals and lots of inflammatory cell(Figure 2B). After two weeks recovery, the crystals declined in number (Figure 2C). After 12 weeks recovery, mesenchymal cells differentiation of renal tubular epithelial cell gradually formed a new renal tubule (Figure 2D).
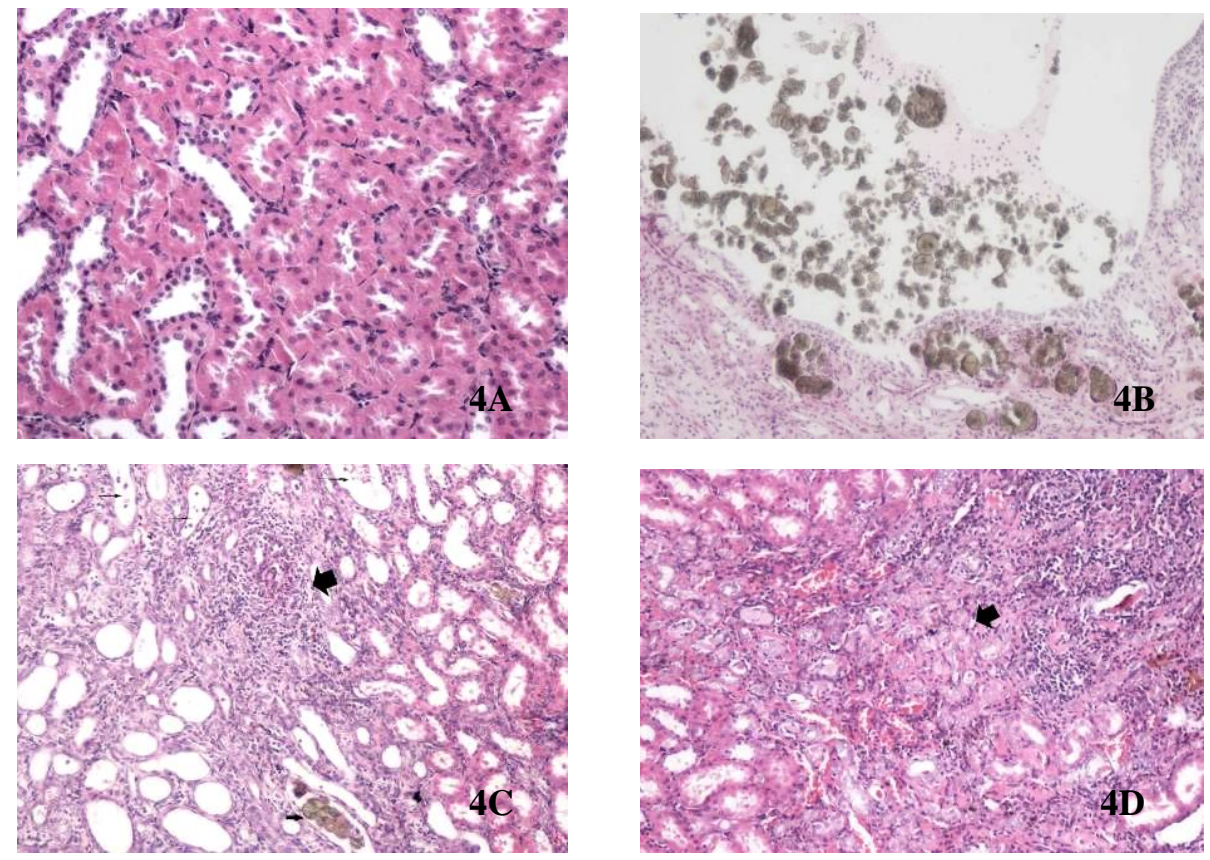

Fig.4 The renal tissues pathological pictures $(\times 100)$.4A control group, 4B after 5 weeks does, 4C after 2 weeks recovery, 4D after 12 weeks recovery.

\section{Discussion}

Intake of melamine alone or melamine-cyanuric acid mixture cause crystals formation in kidney and eventually lead to kidney failure has become a consensus. According to the chemical nature of melamine and cyanuric acid, melamine did not participate in the metabolism of organism, the melamine was acidized by gastric acid in the stomach and part of melamine was most likely hydrolyzed to cyanuric. It had been demonstrated, the melamine was firstly hydrolyzed under the strong acid condition catalyst to format ammeline, ammelide, finally into cyanuric acid by hydrolysis process ${ }^{[11,12]}$. Both the cyanuric acid and melamine without hydrolysis in the stomach were into blood circulation to kidney later. When flowing through the tubular, they were concentrated by the re-absorption. By the process of blood filtration and re-adsorption to form final urine after about 1000 times concentrated. When the concentrations of melamine and cyanuric acid were achieved a certain value, they were connected rely on the molecular structure between the hydroxyl and amino to form hydrated bond ${ }^{[13]}$. This process can be repeated and eventually formatted crystal structure ${ }^{[14]}$. These crystals were difficult to dissolve in water, so they remained in renal tubular, the interface of renal tubular determined the shape of crystals. Due to the different sizes of renal tubular interface, the diameter ranging from $5 \sim 100 \mu \mathrm{m}$ of pathological section was observed under the same vision of microscope. All concentric circles structures of crystals were based on renal tubular interface template. The melamine solution was individually regulated to $\mathrm{pH}$ value of $3,4,5$, and 6 placed in $37^{\circ} \mathrm{C}$ thermostat water bath for acidification which simulated gastric conditions, the reaction time was set at 1,2,and 3 hours, the final solution was tested by GC-MS to analysis the concentration of melamine medicated to cyanuric acid. This vitro experiment confirmed 
that melamine exposure alone hydrolyzed to cyanuric acid under the gastric acid, and the cyanuric acid reacted with non-hydrolyzed melamine became melamine-cyanuric acid crystals, which led to acute renal failure.

However, in the cases of intake of melamine alone cause crystals formation in kidney and eventually lead to kidney failure, the way of melamine transform to cyanuric acid still exists different opinions. One point of view considered klebsiella gut microbiota converted melamine to cyanuric acid, and broad spectrum antibiotics applying to the rats can inhibit the gut microbiota, and then reduce the crystals in kidney ${ }^{[10]}$. However, this study provided another opinion, gastric acid in the stomach converted melamine to cyanuric acid. The rate of melamine hydrolysis depended on the gastric acidity, stronger gastric acid led higher hydrolytic rate. The amount of melamine hydrolysis depended on the residence time in the stomach, longer residence time led to the more amount of melamine hydrolysis. It was implied that the same intake situation may cause different kidney injury level in the melamine exposed cases, which related with gastric acidity and the residence time in stomach. In this study, melamine was administered in the diet to the mice for 4 weeks at dose of $25 \mathrm{mg} / \mathrm{kg} \cdot \mathrm{bw} / \mathrm{d}$. After 5 -week does, BUN and CRE of the serum were unusually, and increased compared with control group with statistical significance. The lesions after five weeks dose were severe, the renal tubular was in a large number of inflammatory cell infiltrated. The renal tubular expansion was more obviously and with a high degree of expansion that showed tubular epithelial debris around the crystals and lots of inflammatory cell. The rats were relying on self-healing without giving any intervention, after 12 weeks recovery, mesenchymal cells differentiation of renal tubular epithelial cell gradually formed a new renal tubule. This result demonstrates that klebsiella gut microbiota maybe not the dominant factor in the formation of cyanuric acid in vivo. Gastric acid can medicate melamine to cyanuric acid, and our animal experiments also proved that the cyanuric acid can format in vivo.

The limitation of this study was that the melamine can medicated to cyanuric acid under the condition of gastric acid in vitro, but not be verified in vivo. Such as the detection of gastric contents after exposure if contains cyanuric acid. The mechanism of cyanuric acid formation in this study is just a preliminary discussion, further in vivo test needs to be confirmed.

\section{Conclusion}

Melamine can be medicated under the chemical reaction, kidney failure can gradually restored without treatment, which estimated the melamine decomposition to cyanuic acid under the action of gastric acid was one of the mechanisms leading to kidney injure.

\section{Acknowledgements}

We thank the colleagues from State Key Laboratory of Urban Water Resource and Environment for their GC-MS analysis assistance.

\section{Conflict of interest statement}

The authors declare that there are no conflicts of interest.

\section{References}

[1] Liu, G. ; Ren, X.; Xia, Z. , 2009. Analysis of urinary system injury in 282 infants feeded by milk powder containing melamine. Journal of Medical Postgraduates. 3, 270-272.

[2] Cathy, A. ; Brown, K.; Robert, H., et al. , 2007. Outbreaks of renal failure associated with melamine and cyanuric acid in dogs and cats in 2004 and 2007.J Vet Diagn Invest.19, 525-531.

[3] Wang, Y. Organic Chemistry. 2002. Beijing Industry Publisher. 727-728.

[4] FDA. ,2007.Interim Melamine and Analogues Safety/Risk Assessment. US A, Rockvile: FDA. 
[5] OECD SIDS. , 2002. Analysis UNEP Publications: Melamine.

[6] Shao, J., Wen, J., Xu, S. , 2007. Study on melamine mechanism. Modern Journal of Animal Husbandry and Veterinary Medicine. 12, 52-54.

[7] Birgit, P.; Robert, H.; Poppenga, L., et al. , 2007. Assessment of melamine and cyanuric acid toxicity in cats. J Vet Diagn Invest. 19, 616-624.

[8] Reimschuesse, I.; Gieseker, C.; Miller, R., et al. , 2008. Evaluation of the renal effects of experimental feeding of melamine and eyanuric acid to fish and pigs. Am J Vet Res. 69, 1217-1228.

[9] Choudhury, D.; Ahmed, Z. , 2006. Drug-associated renal dysfunction and injury. Nat Clin Pract

Nephrol. 2, 80-91 .

[10] Xiaojiao Z, Aihua Z, Guoxiang X. Melamine- Induced Renal Toxicity Is Mediated by the Gut Microbiota[J]. Sci Trans1 Med, 2013, 5:1-9.

[11] Dobson, R.; Motlagh, S.; Quijano, M., et al., 2008. Identificationand characterization of toxicity of contaminants in pet foodleading to an outbreak of renal toxicity in cats and dogs. Toxicol Sci. 106, 251-262.

[12] Feige, K.; Kang, F. ,1998. Clinical biochemistry and biochemistry detection. [M].Beijing:

People hygiene press. 260-261.

[13]Thomas, R.; Kulkarni, G. A., 2007. hydrogen-bonded channel structure formed by a complex of uracil and melamine. Beilstein J Org Chem. 3, 17.

[14]Roy L. M. Dobson, Safa Motlagh, Mike Quijano. Identification and Characterization of Toxicity of Contaminants in Pet Food Leading to an Outbreak of Renal Toxicity in Cats and Dogs[J]. Toxicology Sciences, 2008, 106:251-262. 